\title{
Estudos sociojurídicos: apontamentos sobre teorias e temáticas de pesquisa em sociologia jurídica no Brasil
}

\author{
LÍGHA MORI MADEIRA" \\ FABIANO ENGELMANN"*:
}

\section{Resumo}

Este artigo analisa o papel e as condições da produção científica da pesquisa sociojurídica no Brasil, apresentando as principais vertentes teóricas clássicas e contemporâneas de análise do direito como fenômeno normativo-social, bem como realizando um mapeamento dos principais temas de investigação e de grupos de pesquisa em atividade no país.

Palavras-chave: Sociologia jurídica. Estudos sociojurídicos.

Socio-Legal Studies: notes on theories and research issues in sociology of Law in Brazil

\section{Abstract}

This article examines the role and present condition of socio-legal research in Brazil, by presenting the main classical and contemporary theoretical currents

\footnotetext{
* Doutora em Sociologia. Professora do Departamento e do Programa de Pós-Graduação em Ciência Política da Universidade Federal do Rio Grande do Sul. (Brasil) E-mail: ligiamorimadeira@gmail.com.

** Doutor em Ciência Política. Professor do Departamento e Programa de Pós-Graduação em Ciência Política da Universidade Federal do Rio Grande do Sul. (Brasil) E-mail: fabengel@ gmail.com.
} 
applied in the analysis of Law as a social normative phenomenon, as well as by mapping the main research subjects and research groups in activity in the country. Keywords: Sociology of law. Socio-legal studies.

\section{Apresentação}

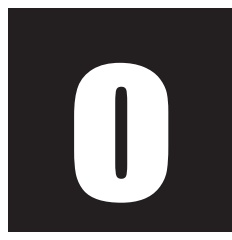

direito, visto ora como um mecanismo de dominação e reprodução, ora como um instrumento de construção de legitimidade e pacificação social, sempre recebeu um olhar privilegiado entre os grandes temas objeto de análise da sociologia. Apesar de sua constituição como um campo de estudos, o estabelecimento de uma disciplina específica, com lugar garantido entre as várias áreas e disciplinas jurídicas, deveu-se a uma grande luta, reflexo das distintas posições de poder que dominam o campo jurídico e sua capacidade de dizer o direito. No Brasil, a trajetória não foi diferente, havendo uma institucionalização tardia, apesar da tradição de análise desenvolvida pela atuação de pesquisadores conhecidos como fundadores da disciplina no país.

Este artigo pretende debater sobre o papel e as condições da pesquisa sociojurídica, de modo a constituir um levantamento dos principais referenciais teóricos e linhas de investigação da Sociologia Jurídica no Brasil. Para tanto, o texto está dividido em quatro seções que discutem o uso da sociologia pelos juristas e as condições para uma sociologia do direito, as origens e o desenvolvimento atual da sociologia jurídica no Brasil, as abordagens teóricas e as diferentes visões sobre o papel do direito na sociologia clássica e contemporânea, finalizando com um mapeamento da produção científica em estudos sociojurídicos no Brasil, através da demonstração das principais temáticas e grupos de pesquisas. O artigo não tem a pretensão de revelar o estado da arte em sociologia jurídica, mas 
demonstrar a repercussão de tais análises, despertando o olhar quanto às possibilidades de pesquisa entre estudantes de direito e ciências sociais.

$2 \mathrm{O}$ uso da sociologia pelos juristas e as condições para uma sociologia do direito

O uso do conhecimento sociológico por parte dos juristas, com muita frequência, traz implícita uma tentativa de redefinição crítica da teoria e dos diversos ramos disciplinares, visando maior aproximação da aplicação das normas ao contexto histórico e social em que se insere o ordenamento. Ou seja, busca-se, através da sociologia, construir um ramo do conhecimento jurídico com foco principal nos aspectos sociais e políticos que circundam a aplicação de normas, a organização do sistema judicial, a formação dos bacharéis e a estruturação das carreiras jurídicas, aspectos que são considerados, por alguns juristas, como "externos" ou estranhos ao mundo do direito.

Esse conteúdo inerentemente social da reflexão sociológica sobre o direito tem sido abordado em dois grandes sentidos: num primeiro, a análise sociológica do direito, tomando conceitos e métodos de pesquisa das Ciências Sociais, é utilizada para a construção de problemas de pesquisa sobre o mundo jurídico, incidindo em diversos temas que não são de interesse imediato para os operadores do direito, mas contribuem, mediatamente, para a melhor compreensão histórica e social do funcionamento do sistema judicial, das carreiras jurídicas, do ensino do direito e sua relação com diversos contextos históricos, sociais, políticos e econômicos. Num segundo sentido, a sociologia é utilizada numa tentativa de redefinição das diversas teorias do direito e ramos disciplinares, visando fundamentalmente uma crítica da dogmática e a fundamentação de um saber voltado para a produção de novas doutrinas capazes de efetivar a 
aplicação do direito num sentido mais político e social, dando apoio à aplicação das normas favoráveis às causas sociais.

Como exemplo da crítica da dogmática através da sociologia jurídica, pode-se mencionar o debate sobre o "direito alternativo" ou o "uso alternativo do direito". Nesse sentido, a sociologia do direito ou sociologia jurídica, assim como o conjunto de fundamentações filosóficas que põe em jogo as definições de Justiça, Estado e Direito, aparecem como recursos teóricos dos juristas que pretendem criticar os segmentos tradicionais que fundamentam o direito a partir da interpretação do conjunto de repertórios legais codificados e reivindicam a autonomia absoluta da ciência jurídica frente às ciências sociais.

O uso da sociologia, em especial nos trabalhos acadêmicos sobre o direito, ocorre também em outros países. Segundo Dezalay, Sarat e Silbey, (1989), para o caso americano, as disputas doutrinárias englobam conflitos entre grupos que se formam no interior do espaço jurídico. A relativa autonomização do palco dessas lutas num espaço universitário mantém uma relação dúbia com o mundo dos práticos, como no caso do movimento de contestação da tradição jurídica americana dos legal realists.

O projeto contestador dos legal realists denunciado por seus adversários como 'bolcheviquização da doutrina', se inscreve assim perfeitamente na estratégia constitutiva de um campo científico que se forma distanciando-se dos 'práticos' e dos interesses que pesam sobre o campo da prática profissional, mas cujos avanços são condicionados pelos ganhos potenciais que eles oferecem a estes mesmos 'práticos' - ou ao menos - às novas categorias de práticos. Esta posição Ihes permite expressar e eufemizar, sob a forma de lutas doutrinárias, os conflitos de interesses entre grupos sociais (Dezalay; Sarat; Silbey, 1989, p. 83). 
O autor referido demonstra como a sociologia do direito norte-americana comporta, num primeiro momento, a crítica ao direito positivo e ao formalismo e, posteriormente, constitui-se como uma aposta profissional de determinadas categorias de juristas. No universo das disputas doutrinárias, a sociologia aparece como importação de conceitos e métodos das Ciências Sociais para as práticas jurídicas, legitimando uma "metodologia crítica" na interpretação das normas. Nesse sentido, constitui-se uma oposição que domina o debate entre os formalistas ou positivistas (ligados à tradição) e os "críticos". Em outras palavras, opõem-se os que afirmam a autonomia absoluta da forma jurídica em relação ao mundo social e os que concebem o direito como um reflexo ou utensílio ao serviço dos dominantes (BOURDIEU, 1986).

Tal fenômeno, no caso americano, envolve também o movimento Law and society, em certa medida sucessor dos juristas-críticos legal realists. O movimento Direito e Sociedade emerge no fim dos anos 60, sendo responsável por um conjunto de reflexões "críticas" acerca do espaço das faculdades de direito tradicionais nos Estados Unidos. Nesse movimento, liderado por professores de direito, entra em jogo também a autonomização relativa do espaço do ensino universitário em relação ao mundo das carreiras práticas. Vauchez (2001) acentua que o sucesso dessa espécie de "crítica do direito", assim como dos estudos sociojurídicos, esteve estreitamente vinculado à criação de um mercado da pesquisa sociojurídica, a partir de 1950. As pesquisas, nesse caso, foram financiadas por fundações privadas e agências governamentais, particularmente nas temáticas do "acesso à Justiça" e da "guerra contra a pobreza". Observase no caso americano algo que é de extrema importância, o papel jogado pelo ensino universitário enquanto espaço de produção intelectual e fundamentação teórica para a crítica do direito. 
No caso brasileiro e no caso francês ${ }^{1}$, a sociologia do direito, além de fundamentar a crítica da tradição jurídica, serve para a tradução de temas sociais para o espaço judicial. Isso ocorre tanto no interior dos cursos de pós-graduação, quanto na expansão do uso dos conhecimentos relacionados a essa disciplina em outras esferas sociais. Entre os casos representativos desses usos está a mobilização do espaço judicial por diversas modalidades de movimentos sociais e ONGs, envolvendo a formalização jurídica de causas políticas e sociais. Isto termina por abrir um amplo leque de novas formas de atuação judiciária, demandando um número cada vez maior de juristas que não façam apenas uma interpretação literal da lei, mas sim uma interpretação crítica e a observação da realidade social.

\section{A sociologia jurídica no Brasil}

Apesar de não pretendermos reconstituir a história da sociologia jurídica no Brasil, é preciso referir as produções teóricas produzidas desde os anos 70, mas prioritariamente a partir dos anos 80, sobre a área e reconhecer o papel de pesquisadores como Joaquim Falcão e Cláudio Souto (1980), Roberto Lyra Filho, Roberto Aguiar (1990), Edmundo Lima Arruda Jr (1988, 1991, 1992, 1993, 2001), José Eduardo Faria (2009, 1984;) e Celso Campilongo (????), José Geraldo de Sousa Jr., Luciano Oliveira (2004), Eliane Junqueira (1993, 2001), e mais recentemente Ana Lucia Sabadell (2002), Antonio Carlos Wolkmer (2001) e Elizabete Novaes (2005).

No Brasil, em sendo a sociologia aplicada ao direito uma demanda antiga, apenas na década de 1990 é que se consegue, por lutas políticas e representações em órgãos de classe, elevar o status da área ao de matéria

\footnotetext{
${ }^{1}$ Ver a respeito da gênese e história do surgimento e legitimação da disciplina de sociologia do direito no espaço acadêmico francês, o conjunto de entrevistas realizado com Jean Carbonnier por Arnaud e Andrini (1995).
} 
obrigatória nos cursos de direito. Tal conquista, fruto da constatação de um exagerado dogmatismo nas ciências jurídicas, que, do ponto de vista da formação acadêmica, acabava por gerar um grande descompasso entre a lei escrita e a realidade social, nasce com a pretensão de humanizar os cursos de direito, tornando o real mais próximo do mundo do direito (Junqueira, 1993).

As bases teóricas do estabelecimento da sociologia jurídica no Brasil retomam os clássicos da sociologia e da sociologia jurídica, apresentando uma visão crítica, histórica, que deve constituir um olhar desnaturalizador sobre as práticas jurídicas e a atuação dos seus operadores.

Desde o início, portanto, o estabelecimento de uma área de estudos sociológicos a respeito de fenômenos jurídicos prima pela valorização de investigações empíricas que pudessem romper com a tradicional pesquisa teórico-bibliográfica, tão afeita à ciência do direito. Nascendo interdisciplinar, a sociologia jurídica, situada na interface entre a sociologia (como área das ciências humanas) e o direito (como área das ciências sociais aplicadas), estabeleceu-se como a disciplina voltada a compreender o tema da produção jurídica (seja do ponto de vista estatal, seja a partir dos inúmeros fenômenos de pluralismo jurídico encontrados na realidade brasileira), ao mesmo tempo em que preocupada com a efetividade do direito (tema recorrente, dada a estrutura desigual de nosso país).

Deixando um pouco de lado todas as dificuldades sofridas para o estabelecimento da sociologia jurídica como área reconhecida e valorizada nas faculdades de direito (dificuldades em muito ainda persistentes), é importante deixar claros os fundamentos da sociologia jurídica brasileira, que sempre pressupôs o direito como fruto de um processo histórico, de embates, móvel e em constante progresso, palco de lutas transformadoras no seio da sociedade civil (Novaes, 2005). 
A respeito de sua importância, são os próprios pesquisadores referência na área que estabelecem:

As grandes transformações que atingiram o Brasil durante os últimos anos - das quais são um importante desdobramento os movimentos em favor dos direitos humanos e de acesso à Justiça, procurando tornar mais efetiva a idéia de que o direito é "universal" e tentando forjar, por meio de lutas políticas, formas alternativas de lei capazes de atenuar as desigualdades sócio-econômicas, abriram caminho para o questionamento da estrutura vigente dos cursos jurídicos. Isso fez com que muitos juristas, pondo em questão as fronteiras tradicionais do direito com as ciências sociais, substituindo abordagens lógico-formais por outras mais críticas e problematizantes, historicizando a análise do direito, identificando os pressupostos ideológicos da dogmática jurídica implícitos na cultura "técnica" dos operadores dos códigos, colocando em novos termos o conceito de "juridicidade", retomando a discussão em torno do pluralismo jurídico, dando um novo tratamento ao problema das fontes do direito e convertendo a eficácia do direito num dos temas obrigatórios da reflexão dos juristas, passassem a defender uma ampla reformulação estrutural desses cursos. (Faria; Campilongo, 1991, p. 25-26).

\section{Abordagens teóricas e as diferentes visões sobre o papel do direito na sociologia clássica e contemporânea}

A sociologia, como ciência voltada à compreensão da sociedade moderna, desde seus primórdios, teve no direito um fenômeno de investigação. Partindo da premissa de que o direito é um fenômeno social, fruto de uma dada realidade, os primeiros sociólogos clássicos buscavam compreender o seu papel na sociedade nascente, apresentando diversas possibilidades para o estudo do papel da norma e da legalidade na regulação da nova sociedade capitalista. 
Aparecem, nessa época, três grandes visões a respeito da função do direito na modernidade, seguidoras ou críticas de referências que não podem ser esquecidas, como Herman Kantorowicz e Eugen Erlich, no século XIX, e antecessoras de autores como Gurvitch e Carbonnier, já no século XX (Souto; Falcão, 1980). Falamos das teorias de Karl Marx, Emile Durkheim e Max Weber.

Estudos marxistas sustentam a crítica ao direito e ao Estado enquanto parte da superestrutura social, responsável pelo controle ideológico e pela manutenção da exploração da camada dominante (Marx, 1988). Tais estudos tiveram grande repercussão e até hoje constituem o marco teórico para análises que buscam compreender o papel das instituições jurídicas em uma sociedade desigual como a capitalista.

O referencial teórico marxista apresenta um papel preponderante na constituição da sociologia jurídica, especialmente a brasileira, pelo seu desenvolvimento a partir dos anos 1970, em meio a repercussões da teoria crítica que atingem o direito. Do ponto de vista universal, o marxismo tem grande contribuição à área da sociologia do direito que discute as relações de trabalho. Atualmente, veremos a grande repercussão da teoria marxista na compreensão dos fenômenos criminais e da política criminal contemporânea (De Giorgi, 2006).

A segunda vertente da sociologia clássica, de matriz funcionalista, constrói a tese de um direito com função socializadora. No paradigma criado por Émile Durkheim (2003), o direito assume o papel de integrador da sociedade, a partir de sua atribuição de introjectar nas pessoas valores e regras necessárias ao bom convívio em sociedade. A tese do direito como instrumento de socialização, aliada à visão do mesmo como símbolo do grau de integração de uma sociedade, recebe grande aceitação tanto na prática do direito quanto nos discursos institucionais, especialmente quando referidos ao controle social, como os observados em prisões e 
instituições para adolescentes, reforçados com o surgimento posterior da concepção de ressocialização. A partir de vertentes sistêmicas, veremos que a concepção funcionalista de sociedade volta a aparecer na sociologia contemporânea, especialmente com autores como Niklas Luhmann, apresentado adiante.

Por fim, a terceira concepção sociológica clássica volta-se a compreender o direito em sua relação com a economia e a política. Seu autor, Max Weber (1999), analisa as relações de legitimidade produzidas pela legalidade jurídica e sua forma corrente de dominação racional-legal. $\mathrm{Na}$ visão weberiana, o direito produz consenso na medida em que age como um produtor de valores sociais. A teorização de Weber a respeito do Estado moderno também é chave para a compreensão do monopólio do poder centrado na atuação estatal.

A teoria weberiana foi absorvida pelas faculdades de direito na compreensão do Estado e da atuação jurídica. Grande parte dos estudos relacionando direito e política partem de um referencial weberiano que permite a discussão a respeito da aceitação obtida pelo poder político a partir de um fundamento processual-legal. A obra de Weber será central também para a construção de teorias sociológicas contemporâneas que pensam o direito, como, por exemplo, a teoria de Habermas.

Quando tratamos da sociologia contemporânea, ou seja, das análises teóricas que buscam compreender o contexto do pós-guerra e as transformações sociais advindas daí, deparamo-nos com várias possibilidades de análise para os fenômenos jurídicos. Percebe-se aí que o direito pode assumir diferentes papéis, dependendo da matriz epistemológica e do tipo de compreensão sociológica a respeito da contemporaneidade que cada teoria apresentará.

Nessa miríade de escolas, acreditamos ser importante fazer referência à contribuição da teoria francesa para a análise do direito atual. 
Destacamos as teses de Michel Foucault (1996, 2001, 2003, 2002), um teórico de matriz desconstrutivista, que lançou um olhar único a respeito do direito e de sua relação com as inúmeras formas de poder e disciplina vigentes na sociedade contemporânea. Sua grande contribuição para os estudos jurídicos dá-se pelas análises históricas a respeito do surgimento do sistema penal moderno e do sistema penitenciário como tendo uma origem medieval e religiosa, bem como servindo a uma apropriação capitalista pelas promessas de controle e vigilância das populações. Outra contribuição da obra foucaultiana está na teorização sobre a biopolítica e a governamentalidade, as formas de atuação do Estado e sua capacidade de gerenciar populações, estabelecendo relação entre saberes e dominação. Em sendo um crítico das concepções de normalidade produzidas pela ciência humana moderna, o autor representa uma das matrizes de contestação das atuações estatais e do direito.

Em termos de estudos, Foucault apresenta-se como um referencial obrigatório para todos aqueles que investigam temas relacionados ao direito criminal e penitenciário, tendo sido uma das primeiras teorias contemporâneas incorporadas à sociologia e à sociologia jurídica brasileiras.

Em outra matriz, encontramos Pierre Bourdieu e sua sociologia construtivista-estruturalista, que permite uma análise crítica muito interessante para a análise do "campo jurídico" e suas relações de dominação e manutenção de poder. Bourdieu conceitua o direito como um espaço definido por regras próprias e um embate entre grupos dominantes e dominados, cuja preocupação central é a reprodução. O autor questiona os pilares do direito moderno como o formalismo e a codificação, apresentando-os como instrumentos voltados à manutenção da dominação entre os profissionais em relação aos profanos. Outra análise bourdiana interessante para a compreensão do direito refere-se aos seus operadores, que, situados nos estratos sociais superiores e dotados de um habitus de classe 
dominante, fazem do direito um campo de sustentação para os demais campos, como o político e o econômico, atuando como um fundamental mecanismo de manutenção do status quo (Bourdieu, 1989, 1999, 2000, 2001; Bourdieu; Teubner, 2000).

Dentre as possibilidades da teoria bourdiana para os estudos sociojurídicos, encontramos as análises sobre o papel e a origem social dos operadores do direito, as críticas ao formalismo e ao rebuscamento da prática jurídica, e análises mais gerais, que criticam a função do direito na sociedade contemporânea (Bourdieu, 2000).

A sociologia alemã também apresenta análises fundamentais para o direito atual. Destacamos as teorias de Niklas Luhmann (1980, 1983, 1989, 1992, 2004, 2005), o autor da nova teoria de sistemas, que, desde sua primeira fase teórica, explica a legitimidade do direito através do procedimentalismo. Luhmann, na segunda fase de sua teoria, ao estabelecer um sistema jurídico fechado (autopoiético) cuja produção de validade dá-se por recursividade, estabelece as bases para a retomada de uma visão de relativa autonomia entre o direito, a política e a economia na sociedade contemporânea.

Na sociologia alemã, outra referência é Jürgen Habermas(2003a, 2003b, 2003c, 2003d), cuja teoria da ação comunicativa é central para compreender o direito, visto pelo autor em duas modalidades: o direito da facticidade (o direito do ser) serve a interesses do sistema político econômico, sendo um instrumento do processo de colonização do mundo da vida, enquanto o direito da validade (o direito do dever-ser) deve ter base ética, fundamentado pela moral, sendo capaz de canalizar as demandas sociais no mundo da vida, contribuindo para uma democratização da sociedade. Entre os exemplos de utilização da teoria habermasiana na análise de contextos jurídicos, encontramos as discussões jusfilosóficas a respeito da moralidade e da justiça no direito, as discussões sobre teoria 
democrática e análises sobre o desenvolvimento societário e sua relação com diferentes tipos de relacionamento social com as normas jurídicas. Cabe citar a obra de Marcelo Neves (1996) como parte de referenciais habermasianos e luhmannianos, que busca compreender as especificidades do direito e da sociedade brasileiros.

Achamos importante referir também o sociólogo do direito Boaventura de Souza Santos (, cujas análises sobre fenômenos de pluralismo jurídico são importantes para a compreensão do contexto brasileiro e seu histórico de exclusão e lacunas na atuação estatal e jurídica. Este autor destaca-se também pelas recentes análises que vem fazendo a respeito dos tribunais e dos sistemas de justiça nos países ocidentais, mas principalmente a respeito do direito e suas experiências democráticas naqueles que chama de "os países de baixo", referindo-se a contextos latinoamericanos e africanos, ressaltando a importância da proteção a direitos humanos (mas dentro de uma concepção multiculturalista e crítica), do desenvolvimento de regras e experiências comunitárias e informais de resolução de conflitos (Santos, 1988).

A obra de Boaventura de Souza Santos, de matriz crítica, demarca sua escolha pela ciência pós-moderna, uma concepção que, desvinculada das matrizes da pós-modernidade francesa, opta por apresentar uma tese na qual o saber popular deve estar na mesma hierarquia do conhecimento científico, visto por ele como elitista e dominador (SANTOS, 1989, 2003a, 2003b, 2003c).

Entre as análises feitas a partir do referencial teórico de Boaventura de Souza Santos, destacamos os estudos sobre pluralismo jurídico, sobre a sociologia dos tribunais, sobre a administração da justiça e as reformas dos Poderes Judiciários em contextos democráticos (SANTOS, 2001, 2002, 2003a, 2003b, 2003c). 


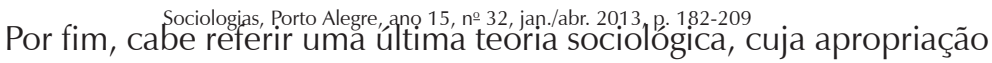
nos cursos de direito ainda é muito restrita, mas que oferece um olhar interessante para a compreensão dos chamados novos temas do direito, como é o caso do direito ambiental, do direito penal econômico e as próprias modificações no direito civil atual. A referência é a teoria da estruturação de Anthony Giddens, que oferece um arcabouço conceitual para compreender a sociedade contemporânea e a produção dos riscos (Giddens, 1991,1997; Giddens; Beck; Lash, 2002). Juntamente com Luhmann, Giddens apresenta-se como um importante referencial para os estudos sociojurídicos que buscam compreender o papel e as configurações dos riscos e perigos, servindo a análises ambientais, criminais e familiais na sociedade atual.

Quando se fala em teoria contemporânea, especialmente voltada à compreensão de fenômenos ligados ao direito, não é possível deixar de lado as produções criminológicas, inseridas no debate sociológico em muitos países do mundo. Salientamos especialmente as discussões produzidas por teorias e autores que buscam compreender o sistema criminal na atualidade e seu inchaço, as relações entre o aumento do uso da prisão e do encarceramento com as modificações no sistema produtivo, bem como a identificação entre o panorama econômico e as formulações políticas estatais. Dentre estes, cabe destacar as produções criminológicas de Jock Young (2002) e David Garland (1993, 2005; Garland; Sparks, 2000), e as teorias de sociologia criminal de Loïc Wacquant (2001a, 2001b, 2003) e Alessandro de Giorgi (2006).

A partir da teoria sociológica contemporânea, percebe-se o quanto a função do direito na atualidade pode estar vinculada a duas grandes visões, por hora dicotômicas, por hora complementares: uma visão crítica, que lhe atribui um papel de dominação e manutenção de poder versus uma visão do direito como instrumento de conquista democrática, de proteção de direitos e garantias. 


\section{Os estudos sociojurídicos no Brasil:} temáticas e grupos de pesquisas

Com o objetivo de conhecer a produção acadêmica de fenômenos sociojurídicos, optamos por mapear a existência de grupos de pesquisa cadastrados no Diretório de Grupos de Pesquisa do CNPq, a partir da seleção de temas-chave, que foram investigados sempre nas áreas de Direito, Sociologia, Ciência Política e Antropologia. A seleção das áreas deveu-se à escolha dos autores de privilegiar o debate nativo do direito e sua análise externa restrita às ciências sociais. A partir de agora, apresentamos os principais temas e exemplos de núcleos de investigação.

O tema violência e criminalidade é um dos principais objetos dos estudos sociojurídicos. O desenvolvimento dessa área de estudos no Brasil é decorrente de um significativo aumento nos índices de criminalidade violenta nos últimos 20 anos, principalmente nos grandes centros urbanos, que tornou imprescindível um novo olhar da ciência e acarretou a constituição de uma série de grupos e núcleos de pesquisa, de relevância nacional e internacional, dos quais se destacam o Grupo de Pesquisa Violência e Cidadania/ UFRGS, o Núcleo de Estudos da Violência/ NEV/ USP, o Grupo de Pesquisa Poder, Violência e Cidadania/ UFC, o Núcleo de Pesquisa das Violências/ NUPEVI/UERJ, o Grupo de Pesquisa Violência, Cidadania e Segurança/ UNB, o Centro de Estudos de Criminalidade e Segurança Pública/CRISP/UFMG e o Grupo Políticas Públicas de Segurança e Administração da Justiça Penal/ PUCRS.

Esta produção, em termos de grupos de pesquisa, concentra-se na sociologia, havendo cadastrados no CNPq 18 grupos que investigam violência e criminalidade nesta área, seguidos por dez grupos cadastrados no direito, seis na ciência política e três na antropologia. 
Gráfico 1. Grupos de Pesquisa em Violência e criminalidade

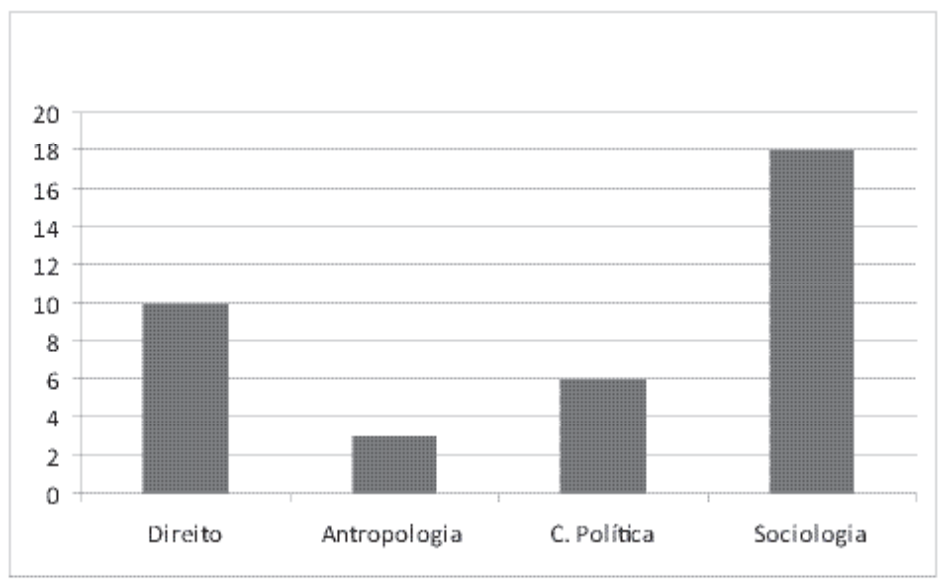

Fonte: Diretório dos Grupos de Pesquisa no Brasil - CNPq, 2011

Especialmente na sociologia brasileira, a violência e a criminalidade vêm se desenvolvendo como um campo de pesquisa diversificado, com estudos abordando os mais variados temas: pobreza e tráfico de drogas, juventude e criminalidade, violência nas escolas, violência doméstica, crimes por encomenda, etc. Há também estudos preocupados com a análise do sistema de justiça e suas instituições de controle social, como a polícia, o Judiciário e o sistema penitenciário. Somados a essa área, estudos em sociologia do crime também analisam o sistema de justiça, as instituições de privação de liberdade, seja de adultos ou de adolescentes, estudos sobre violência e suas várias facetas e estudos em criminologia, enfocando novos tipos de criminalidade, como os delitos transnacionais.

Outra grande área temática para estudos sociojurídicos é a de direitos humanos, que, englobando temas de política (cultura, política e democracia), estudos agrários e ambientais, feminismo e relações de gênero (dentre eles, as análises sobre homicídios de mulheres, identidade, raça), violência 
(violência e cidadania, exclusão e direitos humanos, segurança pública, representações sociais sobre medo, violência, morte e vida, política de drogas e direitos humanos), responde por boa parte das investigações que relacionam o direito às ciências humanas, especialmente a sociologia.

A análise dos grupos de pesquisa demonstra uma concentração na área de direito, com 215 grupos, seguida da sociologia, com 34, da ciência política com 23 e da antropologia, com 21 grupos.

Gráfico 2. Grupos de Pesquisa em Direitos Humanos

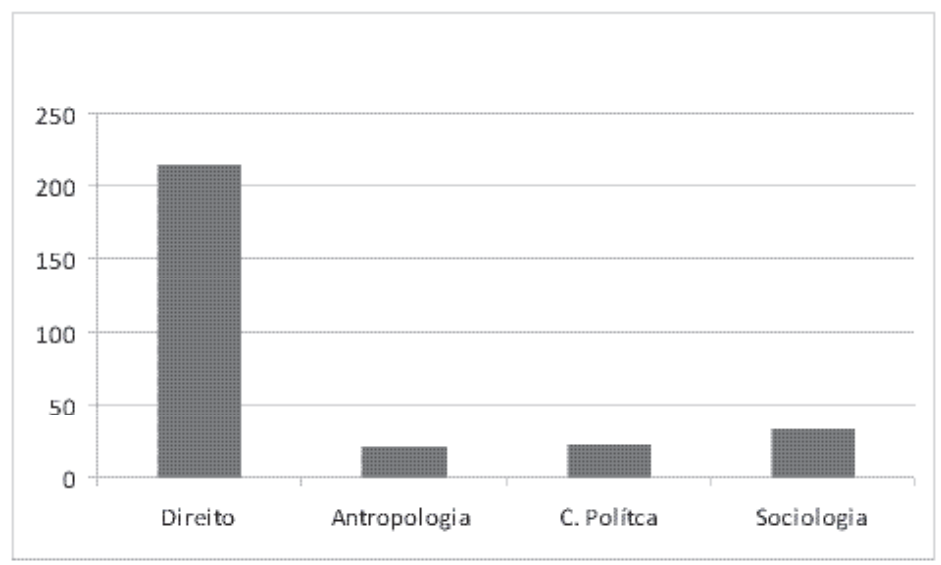

Fonte: Diretório dos Grupos de Pesquisa no Brasil - CNPq, 2011

Dentre os principais núcleos de pesquisa destacam-se o Núcleo de Estudos em criminologia e direitos humanos/ NUESC/ UFF, o Núcleo de Estudos de Gênero/ PAGU/ Unicamp, o grupo de Estudos Políticos/ CEDEC, o Memorial de Direitos Humanos/ UFSC, o grupo de Processos Político-Sociais e Exclusão/ USP e o Núcleo de Antropologia e Cidadania/ $\mathrm{NACl}$ / UFRGS. 
Merece grande destaque também a área de investigação que engloba os estudos sobre acesso à justiça, caracterizados por discutir aspectos constitucionais, institucionais e processuais; efetividade e tempestividade; democratização; acesso à justiça na perspectiva dos direitos humanos; cidadania, direito e justiça; administração de conflitos pelo Judiciário e meios alternativos de resolução; direitos fundamentais e novos direitos; práticas de acesso à justiça; direitos humanos e políticas públicas; efetividade e jurisdição trabalhista; direitos humanos e direito internacional; acesso à justiça e diversidade cultural; política e direito; política criminal e acesso à justiça.

No Diretório de Grupos de Pesquisa do CNPq estão cadastrados 79 grupos de acesso à justiça no direito, cinco na sociologia e um grupo em cada área de ciência política e antropologia.

Gráfico 3. Grupos de Pesquisa em Acesso à justiça

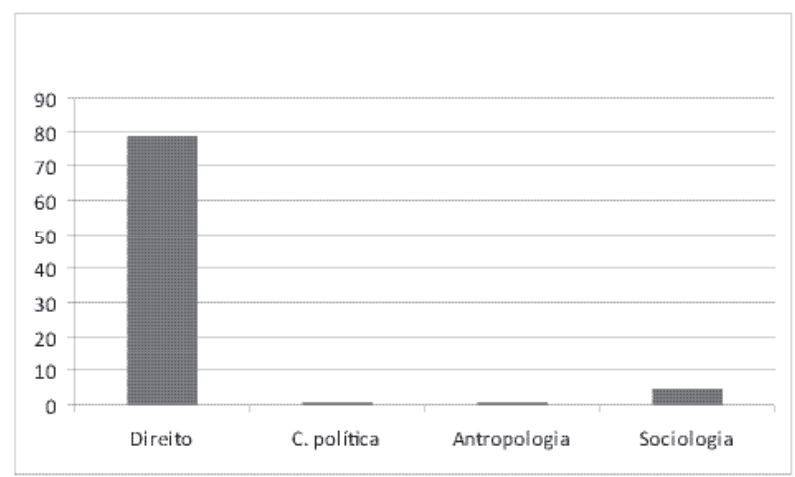

Fonte: Diretório dos Grupos de Pesquisa no Brasil - CNPq, 2011

Núcleos como o Gênero e Sociedade/ UFMG, o Grupo de Estudos em Violência e Administração de Conflitos/ UFSCAR, o NADIR - Núcleo de Antropologia do Direito/ USP, o Núcleo de Pesquisa sobre Políticas de Prevenção da Violência e Acesso à Justiça e Educação em Direitos Huma- 
nos/ UFRJ e o Grupo de Pesquisas sobre Política e Direito/ Unicamp são exemplos de produção de investigações nesta área.

Na discussão sobre instituições jurídicas, especialmente tribunais e sociedade, encontramos 31 grupos de pesquisa cadastrados no direito, dois na ciência política e um na sociologia. Estes grupos fazem estudos sobre configurações institucionais e relações de trabalho; república e instituições político-jurídicas; reforma do Estado e legislação agro-ambiental; sociedade, representações e processos sociais. As pesquisas sobre estes temas são desenvolvidas em núcleos como o Núcleo de Pesquisas sobre Práticas e Instituições Jurídicas/ UFF, Configurações Institucionais e Relações de Trabalho/ UFRJ e o Observatório da Justiça Brasileira/ UFRJ.

Gráfico 4. Grupos de Pesquisa em Instituições jurídicas, tribunais e sociedade

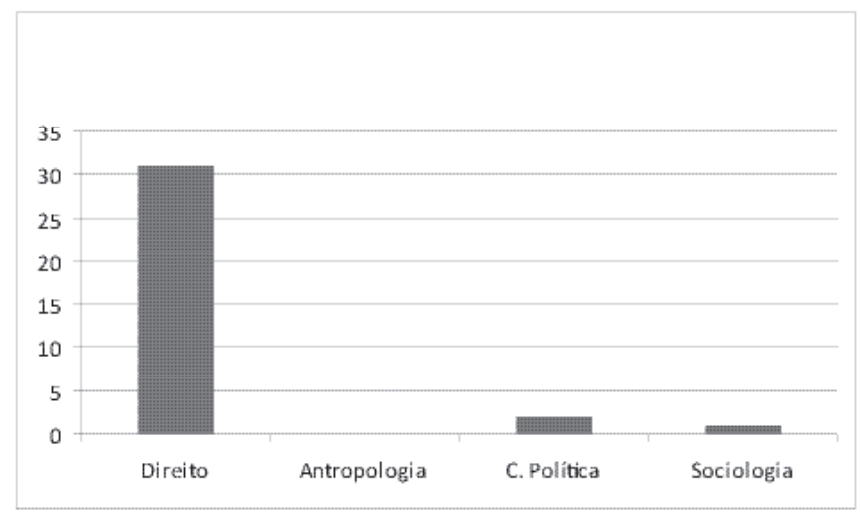

Fonte: Diretório dos Grupos de Pesquisa no Brasil - CNPq, 2011

Outra área importante de investigação sociojurídica caracterizada pela interdisciplinaridade é a criminologia. Com a grande maioria dos grupos concentrados no direito (36 grupos) e apenas dois grupos em cada área de sociologia e antropologia, destacam-se os grupos Crime e Socie- 
dade/ UFMG, Criminologia e Mídia/ PUCRS, o Grupo de Estudos de Criminologia Crítica/ UFPR, o Grupo de Estudos e Pesquisas em Criminologia/ GEPCRIM/ PUCRS e o Núcleo de Estudos em Criminologia e Direitos Humanos/ NUESC/ UFF.

Gráfico 5. Grupos de Pesquisa em Criminologia

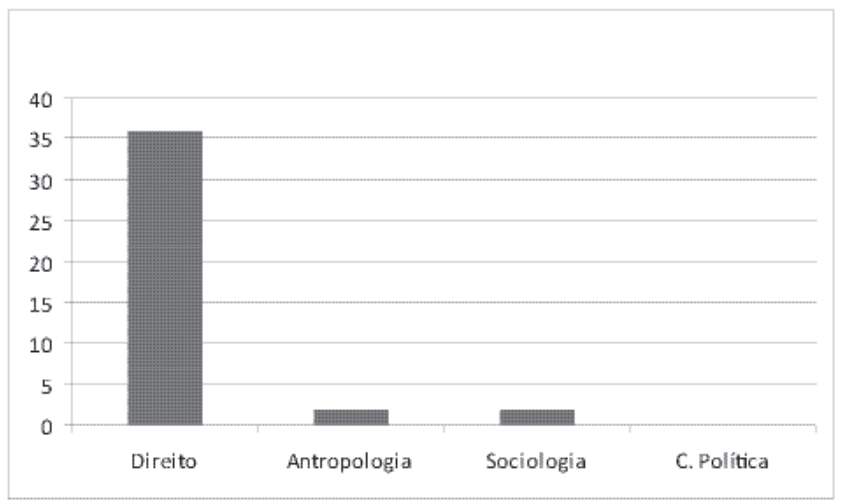

Fonte: Diretório dos Grupos de Pesquisa no Brasil - CNPq, 2011

A discussão sobre política e direito é feita por 121 grupos de direito, 15 de ciência política, onze de antropologia e seis de sociologia. Nessa área, encontramos investigações sobre política, sociologia e direito; sociologia das profissões jurídicas; inter e transdisciplinaridade; direito ambiental; direito sustentável; linguagem e direito; instituições e atores no direito do trabalho; modelos e paradigmas jurídicos; Poder Judiciário, conflito e sociedade; além das discussões sobre violência e criminalidade já referidas anteriormente. Podemos destacar como principais núcleos de investigação o grupo Poder Judiciário, Conflito e Sociedade/ FGVRJ, o grupo Sociologia das Profissões/ UFSCar, o NEPP - Núcleo de Estudos em Políticas Públicas/ UNICAMP, o Núcleo de Estudos em Justiça e Poder 
Político/ UFRGS, o Núcleo de Pesquisa em Política, Sociologia e Direito/ NEP/ UFU, o Núcleo de Pesquisa em Sociologia Jurídica/ UFOP e o grupo Sociologia, Direito e Justiça/ UFF.

Gráfico 6. Grupos de Pesquisa em Política e direito

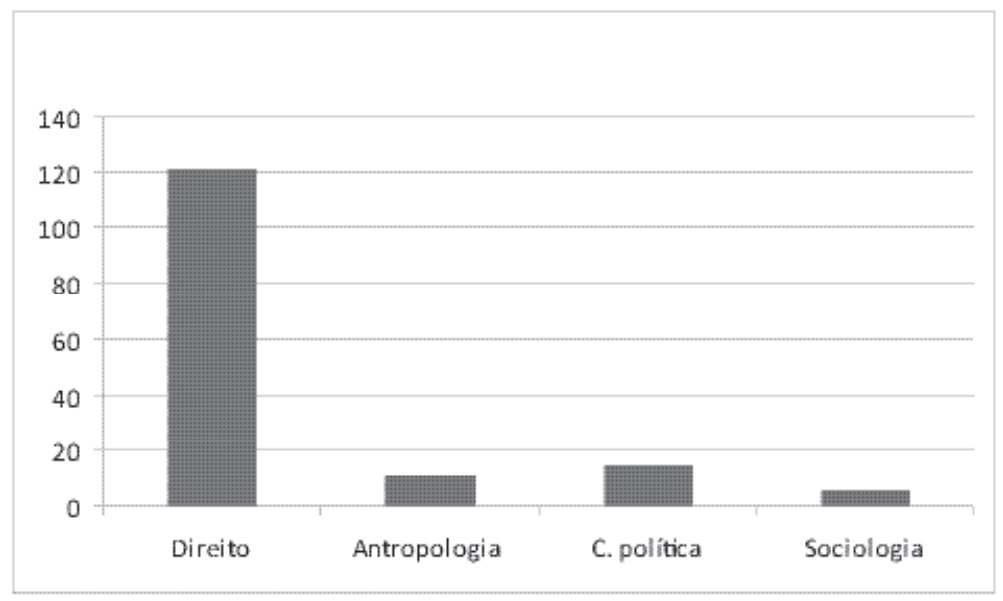

Fonte: Diretório dos Grupos de Pesquisa no Brasil - CNPq, 2011

Por fim, outro tema fundamental de investigação é a relação entre direito e democracia, investigada por 85 grupos em direito, oito grupos de ciência política e seis de sociologia. Dentre eles, o Centro de Estudos dos Partidos Políticos Latino-Americanos/ UFSCAR, o grupo Direito à Verdade e à Memória e Justiça de Transição/ PUCRS, o grupo Direito e Ações Afirmativas: direitos humanos na diversidade, o Grupo de Estudos em Teoria Política Moderna/ USP, Instituições Políticas e Processo Legislativo/ UFPR e o Moinho Jurídico - Mostruário de Observação Social do Direito/ UFPE. 
Gráfico 7. Grupos de Pesquisa em Direito e democracia

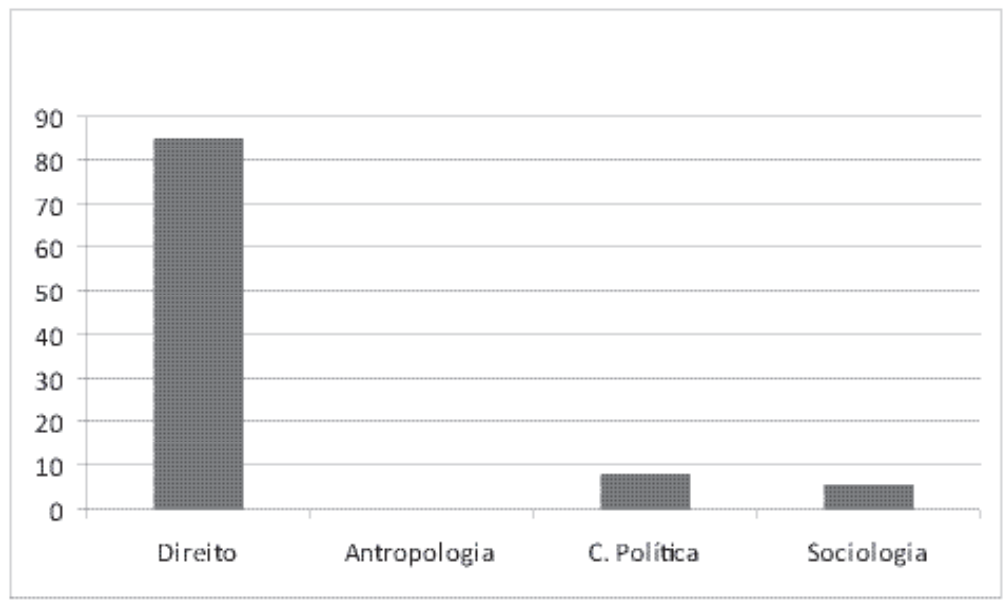

Fonte: Diretório dos Grupos de Pesquisa no Brasil - CNPq, 2011

Desse pequeno balanço da produção na área, percebe-se uma preocupação da sociologia jurídica em investigar o direito a partir das especificidades sociais brasileiras, não sendo possível compreendê-lo sem situá-lo como produção normativa em contextos sociais de exclusão e subcidadania. Acreditamos que o problema do acesso, da organização e dos operadores do sistema de justiça, dos fenômenos de pluralismo jurídico e dos mecanismos formais e informais de resolução de conflitos, sempre pelo viés da desigualdade social e da não efetivação de direitos a todas as parcelas da população, são temas-chave para a compreensão da função de nosso direito.

Além disso, são também fundamentais as discussões sobre sociologia política e o papel do direito na relação com os processos de racionalização, legitimação e construção da cidadania. Não podemos deixar de mencionar todas as discussões realizadas sob o enfoque da teoria so- 
ciológica, privilegiando várias concepções epistemológicas de análise do fenômeno jurídico, ora sob o enfoque da sociologia clássica, ora da contemporânea, seja em perspectivas sistêmicas, estruturalistas e suas derivações. Por outro lado, a discussão sobre o ensino jurídico também aparece nos debates sociológicos, por se entender crucial discutir o nosso papel no ensino superior brasileiro e na formação profissional.

Merecem destaque também os temas sobre os fenômenos criminais. Em sendo este um tema caro à sociedade brasileira e cuja interface entre o direito e a sociologia se dá de maneira bastante crucial, a discussão sobre o crime e suas formas de contenção, sobre a atuação do Estado a partir do sistema de justiça criminal e de outras instituições, as análises criminológicas e de perfil criminal sempre suscitaram, por parte dessa área, um papel preponderante, por pressupor-se ser este um dos mais graves problemas da sociedade brasileira pós-democratização.

\section{Algumas reflexões finais}

Da apresentação, entre perspectivas teóricas, condições e possibilidades para o desenvolvimento da sociologia jurídica e principais temáticas e grupos de investigação no Brasil, fica visível a importância dessa área e desse olhar crítico sobre o direito. Uma vez que a sociologia busca compreender as transformações econômicas, políticas e culturais e as formas de organização da vida social, o direito sempre se revelou um temachave, eis que toda a teoria sociológica sempre esteve preocupada com o conhecimento sobre a manutenção e a alteração das relações de poder na sociedade. Nosso pressuposto é o de que não se pode compreender o que é o direito, suas funções, sua relação com outras áreas ou campos sociais, sem o auxílio de um viés sociológico. Nesse sentido, é fundamental entender o direito no bojo das relações sociais, analisar o seu papel frente 
às configurações da sociedade, especialmente a nossa sociedade, marcada profundamente pela desigualdade social, a carência de cidadania e a precariedade de acesso à justiça para os grupos sociais vulneráveis.

Se a sociologia sempre teve um papel crucial no direito, a análise da defasagem da ordem jurídica em relação às práticas sociais e o despertar de consciências críticas, em contraponto a discussões eminentemente dogmáticas, levam à necessidade de trabalhar com uma base empírica para a especulação teórica, que seja capaz de ir contra a máxima de que o direito tem retórica demais e realismo de menos (Oliveira, 2004). É incumbência da sociologia jurídica realizar parte da formação do cientista do direito, um profissional que, além da dominância da dogmática, seja capaz de compreender o direito em seus aspectos sociais, de vislumbrar que direito é feito para que sociedade, enfim, de conhecer o direito em sua capacidade integral, ora como solucionador de conflitos, pacificador social, ora como mantenedor das estruturas sociais, legitimador dos sistemas econômico e político.

\section{Referências}

A seguir apresentamos uma listagem de referências para a investigação em sociologia e sociologia jurídica. Optamos por dividir em tópicos, de modo a melhor possibilitar a compreensão.

Sociologia jurídica e sociologia jurídica brasileira

AGUIAR, Roberto Armando Ramos de. Direito, Poder e Opressão. São Paulo: Alfa-Omega, 1990.

ARNAUD, André-Jacques; ANDRINI, Simona. Jean Carbonnier, Renato Treves et la sociologie du droit: archéologie d' une discipline. Paris: LGDJ, 1995.

ARRUDA JUNIOR, Edmundo Lima de. Direito, Marxismo e Liberalismo: Ensaios para uma Sociologia Crítica de Direito. Florianópolis: CESUSC, 2001. 
ARRUDA JUNIOR, Edmundo Lima de. Introdução à Sociologia Jurídica Alternativa: ensaios sobre o Direito numa sociedade de classes. São Paulo: Acadêmica, 1993.

ARRUDA JUNIOR, Edmundo Lima de. Lições de Direito Alternativo 1. São Paulo: Acadêmica, 1991.

ARRUDA JUNIOR, Edmundo Lima de. Lições de Direito Alternativo 2. São Paulo: Acadêmica, 1992.

ARRUDA JÚNIOR, Edmundo Lima. Advogado e Mercado de Trabalho: um ensaio sobre a crise de identidade sócio-profissional dos bacharéis em direito no Brasil. Campinas: Julex, 1988.

CAMPILONGO, Celso Fernandes. Direito e Democracia. 2. ed. São Paulo: Max Limonad, 2000.

DEZALAY, Yves; SARAT, Austin; SILBEY, Susan. D'une démarche contestataire à un savoir méritocratique Esquisse d'une histoire sociale de la sociologie juridique américaine. Actes de la Recherche en Sciences Sociales, Paris, n. 78, juin 1989.

FARIA, José Eduardo. (Org.) A Crise do Direito numa Sociedade em Mudança. Brasília: UNB, 2009.

FARIA, José Eduardo. Sociologia Jurídica: Crise do Direito e Práxis Política. Rio de Janeiro: Forense, 1984.

FARIA, José Eduardo; CAMPILONGO, Celso. A Sociologia Jurídica no Brasil. Porto Alegre: Fabris, 1991.

JUNQUEIRA, Eliane Botelho. A sociologia do direito no Brasil: introdução ao debate atual. Rio de Janeiro: Lumen Juris, 1993.

JUNQUEIRA, Eliane Botelho; OLIVEIRA, Luciano. (Org.) Ou Isto Ou Aquilo: A Sociologia Jurídica nas Faculdades de Direito. Rio de Janeiro: Letra Capital, 2002. JUNQUEIRA, Eliane. Botelho. Entrevista. Caderno de Direito da Universidade Federal de Sergipe, São Cristóvão, v. 4, n. 1, 2001.

NOVAES, Elizabete David. Perspectiva sociológica e pluralismo jurídico: a necessidade de superação do bacharelismo-tecnicista na formação do profissional do direito. Revista Sociologia Jurídica, n. 1, jul-dez 2005. Disponível em: < http:// sociologiajur.volabol.uol.com.br/rev01 novaes.htm>. Acesso em: 20 ago. 2009.

OLIVEIRA, Luciano. Sua Excelência, o Comissário e outros ensaios de Sociologia Jurídica. Rio de Janeiro: Letra Legal, 2004.

ORDEM DOS ADVOGADOS DO BRASIL. OAB Ensino Jurídico: 170 anos de cursos jurídicos no Brasil. Brasília: Conselho Federal da OAB, 1997.

ORDEM DOS ADVOGADOS DO BRASIL. OAB Ensino Jurídico: Diagnóstico, perspectivas e propostas. Brasília: Conselho Federal da OAB, 1992. 
ORDEM DOS ADVOGADOS DO BRASIL. OAB Ensino Jurídico: Novas diretrizes curriculares: Brasília: Conselho Federal da OAB, 1996.

SABADELL, Ana Lúcia. Manual de Sociologia Jurídica: Introdução a uma leitura externa do Direito. 2. ed. São Paulo: RT, 2002.

SOUTO, Cláudio; FALCÃO, Joaquim. Sociologia e Direito: leituras básicas de sociologia jurídica. São Paulo: Pioneira, 1980.

VAUCHEZ, Antoine. Entre droit et sciences sociales: Retour sur l'histoire du mouvement Law and society. Genèses, n. 45, p. 134-149, déc. 2001.

WOLKMER, Antonio Carlos. Introdução ao pensamento jurídico crítico. 3. ed. São Paulo: Saraiva, 2001.

\section{Teoria sociológica clássica}

DURKHEIM, Émile. As regras do método sociológico. São Paulo: Martin Claret, 2003.

DURKHEIM, Émile. Da divisão do trabalho social. 2. ed. São Paulo: Martins Fontes, 2004.

DURKHEIM, Émile. O suicídio. São Paulo: Martins Fontes, 1997.

FREUND, Julien. A sociologia de Max Weber. Rio de Janeiro: Forense Universitária, 2003.

MARTINS, Carlos Benedito. O que é sociologia. Brasília: Ed. Brasiliense, 2006.

MARX, Karl. A questão judaica. São Paulo: Centauro, 2003.

MARX, Karl. O capital. 3. Ed. São Paulo: Nova Cultural, 1988.

MARX, Karl. Prefácio. In: MARX, Karl. Para a Crítica da Economia Política. 2007. [Documento eletrônico] Disponível em: <http://www.marxists.org/portugues/ marx/1859/01/prefacio.htm>. Acesso em: 20 jul. 2009.

MARX, Karl; ENGELS, Friedrich. O manifesto comunista. São Paulo: Centauro, 2006. WEBER, Max. A ética protestante e o espírito do capitalismo. São Paulo: Companhia das Letras, 2004.

WEBER, Max. Ciência e política: duas vocações. São Paulo: Martin Claret, 2006. WEBER, Max. Economia e sociedade. Brasília: UNB, 1999.

Teoria sociológica e criminológica contemporânea

BOURDIEU, Pierre. A força do direito: elementos para uma sociologia do campo jurídico. In: BOURDIEU, P. O poder simbólico. Rio de Janeiro: Bertrand do Brasil, 1989. p. 209-254. 
BOURDIEU, Pierre. Meditações pascalinas. Rio de Janeiro: Bertrand Brasil, 2001. BOURDIEU, Pierre. Questiones de sociologia. Madrid: Istmo, 2000.

BOURDIEU, Pierre. Razones practicas: Sobre la teoría de la acción. Barcelona: Ed. Anagrama, 1999.

BOURDIEU, Pierre; TEUBNER, Gunter. La fuerza del derecho. Bogotá: Ed. Uniandes, 2000.

DE GIORGI, Alessandro. A miséria governada através do sistema penal. Rio de Janeiro: Revan, 2006.

FOUCAULT, Michel. A Verdade e as Formas Jurídicas. 2. ed. Rio de Janeiro: Nau Ed., 2001.

FOUCAULT, Michel. Ditos e escritos IV: Estratégia, poder-saber. Rio de Janeiro: Forense Universitária, 2003.

FOUCAULT, Michel. Microfísica do poder. Rio de Janeiro: Graal, 2002.

FOUCAULT, Michel. Vigiar e Punir: História da violência nas prisões. 14. ed. Petrópolis: Vozes, 1996.

GARLAND, David. El cultura del control. Barcelona: Editorial Gedisa, 2005.

GARLAND, David. Punishment and modern society. Chicago: Chicago University Press, 1993.

GARLAND, David; SPARKS, Richard. Criminology and social theory. Oxford: Oxford UK, 2000.

GIDDENS, Anthony. As conseqüências da modernidade. São Paulo: UNESP, 1991.

GIDDENS, Anthony. Modernidade e identidade. Rio de Janeiro: Jorge Zahar Ed. 2002.

GIDDENS, Anthony; BECK, Ulrich; LASH, Scott. Modernização reflexiva: política, tradição e estética na ordem social moderna. São Paulo: UNESP, 1997.

HABERMAS, Jürgen. Consciência moral e agir comunicativo. Rio de Janeiro: Tempo Brasileiro, 2003d.

HABERMAS, Jürgen. Direito e democracia: entre a facticidade e a validade. Rio de Janeiro: Tempo Brasileiro, 2003a.

HABERMAS, Jürgen. Mudança estrutural da esfera pública. Rio de Janeiro: Tempo Brasileiro, 2003c.

HABERMAS, Jürgen. Teoría de La acción comunicativa. Madrid: Taurus; Santilliana, 2003b. 
LUHMANN, Niklas. A legitimação pelo procedimento. Brasília: UNB, 1980.

LUHMANN, Niklas. A restituição do décimo segundo camelo: do sentido de uma análise sociológica do direito. In: ARNAUD, André-Jean; LOPES JUNIOR, Dalmir (Org.). Niklas Luhmann: do Sistema Social à Sociologia Jurídica. Rio de Janeiro: Lumen Juris, 2004.

LUHMANN, Niklas. Ecological Communication. Chicago: Chicago University Press, 1989.

LUHMANN, Niklas. Observaciones de la modernidad: racionalidad y contingência em la sociedad moderna. Barcelona: Ed. Paidós, 1992.

LUHMANN, Niklas. Risk: a sociological theory. Berlim: Aldine de Gruyter, 2005.

LUHMANN, Niklas. Sociologia do Direito. Rio de Janeiro: Tempo Brasileiro, 1983.

NEVES, Marcelo. Habermas, Luhmann e o Estado de Direito. Lua Nova: Revista de Cultura e Política, São Paulo, n. 37, p. 93-106, 1996.

SANTOS, Boaventura de Souza. Crítica da razão indolente: contra o desperdício da experiência. São Paulo: Cortez, 2002.

SANTOS, Boaventura de Souza. Introdução a uma ciência pós-moderna. 6. ed. Porto: Afrontato, 1989.

SANTOS, Boaventura de Souza. O discurso e o poder: Ensaio sobre a sociologia da retórica jurídica. Porto Alegre: Sergio Fabris, 1988.

SANTOS, Boaventura de Souza. Pela mão de Alice: O social e o político na pósmodernidade. 8. ed. São Paulo: Cortez, 2001.

SANTOS, Boaventura de Souza. Poderá o direito ser emancipatório? Revista Crítica de Ciências Sociais, Coimbra, v. 65, p. 3-76, maio 2003b.

SANTOS, Boaventura de Souza. Reconhecer para libertar: Os caminhos do cosmopolitismo multicultural. Rio de Janeiro: Civilização Brasileira, 2003c.

SANTOS, Boaventura de Souza. Um discurso sobre as ciências. São Paula: Cortez, 2003a.

WACQUANT, Loïc. As prisões da miséria. Rio de Janeiro: Jorge Zahar, 2001a.

WACQUANT, LOÏc. Os condenados da cidade: um estudo sobre a marginalidade avançada. Rio de Janeiro: Revan, 2001b.

WACQUANT, Loïc. Punir os pobres: a nova gestão da miséria nos Estados Unidos. Rio de Janeiro: Revan, 2003c.

YOUNG, Jock. A sociedade excludente. Rio de Janeiro: Revan, 2002. 